\title{
An Empirical Study on the Relationship between the balance of treasure Yield and the Interest Rate of Treasury Bonds
}

\author{
Zeyang Rong \\ Institute of Finance, University of International Business and Economics, Beijing, 100029, China
}

Keywords: The Balance of treasure yield; the interest rate of treasury bonds; vector autoregression

\begin{abstract}
The balance of treasure as a representative of the Internet financial products have closely related with the traditional financial market bonds. In this paper, we study the relationship between the balance of treasure yield and the interest rate of treasury bonds by establishing the vector autoregressive model. The results show that the balance of treasure yield and the interest rate of treasury bonds constitute a two-way causal relationship. The balance of treasure yield and the interest rate of treasury bonds are mainly affected by the lag influences. The balance of treasure should strengthen the risk management, the traditional financial markets should update the concept of innovation, the relevant departments should make appropriate and effective supervision to protect the financial market security.
\end{abstract}

\section{Introduction}

Alipay Company officially launched the balance of treasure with Tianhong Fund Company on June 13, 2013 which can solve the problem of third-party platform precipitation funds and increase the user "sticky". The balance of treasure is a monetary fund, it will make the company's fund direct marketing system built in Alipay system, Alipay users transferred money to the balance of treasure is equivalent to the purchase of Tianhong Fund's profits, the balance of treasure funds deposited by the Tianhong Fund Management, which equal to the investment of monetary funds, the investment income and the user are shared with third-party payment platform.

Monetary funds featured with high security, high liquidity, and stable profitability. Monetary funds mainly invest in short-term monetary instruments, such as bank agreement deposits, the best liquidity bonds, notes, high-rated credit debt. In the balance of treasure, Tianhong Fund Management Company provide monetary fund investment management services, and charge $0.30 \%$ of the management fee and $0.25 \%$ of the sales service fee according to the size of the fund, but also it need to pay Alipay company about $0.25 \%$ of the technical service fee, which prompted the fund managers to strive to do high yield and attract huge amounts of money to purchase.

Table 1 show the share of the balance of treasure in bonds during the reporting period, which shows that the bond in the balance of the treasure portfolio accounted for an important position. As the best security and best-selling varieties in the bond market, the relationship between the balance of treasure yield and the bond interest rate can be simplified to study its relationship with the interest rate of the national debt.

The balance of treasure once is launched; it caused extensive discussion of the community. Some people think that the balance of money as a representative of the Internet financial products, it improves the efficiency of resource allocation, and promote the interest rate market reform. Some people think that it impacts the traditional financial markets, pulled up the financing of the real economy costs. This paper will establish a vector autoregressive model quantitative to study the relationship between the balance of treasure yield and the interest rate of treasury bonds, and then explore the balance of wealthy Internet financial products and traditional financial markets, making suggestions to participating parties in the market for reference. 
Table 1 The proportion of bonds in the balance of treasure investment

\begin{tabular}{|c|c|c|}
\hline Reporting Period & Size & Proportion \\
\hline $2013-12-31$ & 1903.76 & 6.7 \\
\hline $2014-12-31$ & 5792.4 & 7.83 \\
\hline $2015-12-31$ & 6255.21 & 24.6 \\
\hline 2016-12-31 & 8107.14 & 11.5 \\
\hline $2017-3-31$ & 11412.2 & 16.0 \\
\hline 2017-6-30 & 14318.05 & 7.94 \\
\hline
\end{tabular}

Source: Daily Fund Network Tianhong Zengli Bao Money Market Fund Periodic Report Fund size units: Billion yuan

\section{Empirical modeling}

Data selection instructions. This paper chooses the balance of treasure yield and the interest rate of treasury bondsdates which are from June 3, 2013 to May 5, 2017. It makes 980 group of data to be modeled. The statistical software used is Eviews 6.0. The descriptive statistics of the seven-day annualized yield and one-year maturity of interest are shown in Table 2

Table 2 The descriptive statistics of the balance of treasure yield and the interest rate of treasury bonds

\begin{tabular}{llll}
\hline Statistical & indicators & YEB & GZ \\
\hline & Mean & 3.855222 & 2.916568 \\
& Median & 4.034000 & 2.991800 \\
& Maximum value & 6.763000 & 4.250300 \\
& Minimum value & 2.295000 & 1.640700 \\
& Standarddeviatio n & 1.115811 & 0.634083 \\
& Skewness & 0.365266 & 0.137079 \\
& Kurtosis & 2.410225 & 1.831834 \\
\hline
\end{tabular}

From the above table we can see the balance of the seven-day annualized rate of return is $4.034 \%$, one-year treasury interest rate is $2.9918 \%$, Figure 1 shows the balance of seven years of annualized rate of return and one-year treasury interest rate chart, YEB and Shibor trends and fluctuations have a certain degree of similarity, there is a need for further research.

VAR model.

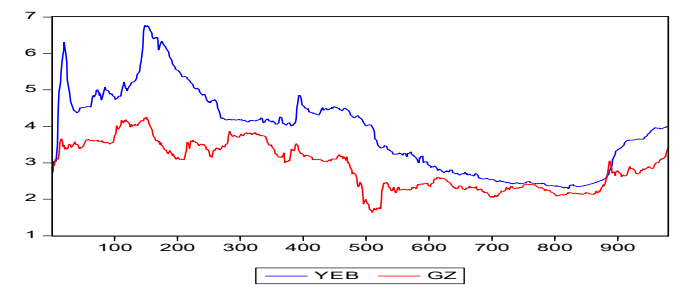

Figure 1 the balance of seven years of annualized rate

(1)Determine the lag order

Before establishing the VAR model, you need to first determine the lag order of the model. There are usually five ways to determine the lag order: LR test, FPE, AIC information criterion, SC information criterion, HQ information criterion. The results are shown in Table 3, and four of the five evaluation indicators considered that the VAR (4) model should be established, thus determining that the lag order is 4 . 
Table 3 Lag order test

\begin{tabular}{lllllll}
\hline \hline Lag & LogL & LR & FPE & AIC & SC & HQ \\
0 & 3211.790 & NA & $4.71 \mathrm{e}-06$ & -6.590945 & -6.580922 & -6.587131 \\
1 & 3457.291 & 489.4887 & $2.87 \mathrm{e}-06$ & -7.086839 & -7.056769 & -7.075396 \\
2 & 3483.434 & 52.01729 & $2.74 \mathrm{e}-06$ & -7.132307 & $-7.082190^{*}$ & -7.113235 \\
3 & 3494.227 & 21.43163 & $2.70 \mathrm{e}-06$ & -7.146257 & -7.076093 & -7.119555 \\
4 & 3507.702 & $26.70178^{*}$ & $2.65 \mathrm{e}-06^{*}$ & $-7.165713^{*}$ & -7.075502 & $-7.131383^{*}$ \\
5 & 3510.228 & 4.993747 & $2.66 \mathrm{e}-06$ & -7.162685 & -7.052428 & -7.120726 \\
\hline \hline
\end{tabular}

(2)Granger causality test

Before establishing the VAR model, a Granger causality test is required to determine the relationship between variables. If a variable is affected by the lag of other variables, then there is Granger causality between them.

The results of the test are shown in Table 4, according to the associated probability, at 5\% significance level, reject "dgz is not the cause of the dyeb Granger", that is, dgz is the dye of the Granger cause, refused "dyeb is not dgz Ranger reason ", that is, dyeb is dgz Granger reasons. The balance of the seven-year annualized rate and one-year interest rate dgz bonds constitute a two-way causal relationship

Table 4 Granger causality test

\begin{tabular}{llcl}
\hline \multicolumn{1}{c}{ Hypothesis } & Statistics & probability & result \\
\hline dgz is not cause of dyeb Granger & 6.54560 & $3 . \mathrm{E}-05$ & refuse \\
dyeb is not dgz Ranger reason & 6.08614 & 3.E-05 & refuse \\
\hline
\end{tabular}

(3)Build the VAR model

The vector autoregressive model (VAR) builds a model based on the statistical properties of the data. It used each endogenous variable in the system as a function of the lag value of all the endogenous variables in the system. It is often used to analyze the variables in the system when the economic system is subjected to some impact yynamic changes, and the contribution of each shock to changes in endogenous variables, explaining the actual impact of economic shocks on variable systems. The empirical results of the VAR model are as follows:

dyeb $=0.4468$ dyeb $(-1)+0.2219$ dyeb $(-2)-0.0439$ dyeb $(-3)+0.0199$ dyeb $(-4)+0.0017 \mathrm{dgz}(-1)+$ $0.0321 \operatorname{dgz}(-2)+0.0311 \operatorname{dgz}(-3)+0.1575 \operatorname{dgz}(-4)+0.0003 \ldots(1)$

Logarithmic likelihood=1688.717, Akaike AIC $=-3.445573$, Schwarz SC=-3.400504

$\mathrm{dgz}=-0.0039$ dyeb $(-1)-0.0086$ dyeb $(-2)+0.1360$ dyeb $(-3)-0.0686 \operatorname{dyeb}(-4)+0.2893 \mathrm{dgz}(-1)+$ $0.0435 \mathrm{dgz}(-2)+0.0606 \mathrm{dgz}(-3)-0.0421 \mathrm{dgz}(-4)+0.0001 \ldots(2)$

Logarithmic likelihood=1823.462, Akaike AIC=-3.721973, Schwarz SC=-3.676904

In the vector autoregressive equation (1), the logarithmic likelihood is large, the values of AIC and SC are very small, and the equation returns well.The seven-year annualized yield is mainly affected by its own lag, and the one-year maturity is also an important factor. According to the logarithmic likelihood and the AIC criterion, the SC criterion shows that the vector autoregressive equation (2) returns well. The maturity of one-year Treasury bonds is affected by its own lag and balance.

(4)Stability Test of VAR Model

Unstable VAR models cannot do impulse response function analysis, so test the stability of the model. As shown in Fig. 2, all eigenvalues are in the unit circle and are not particularly close to the characteristic roots of the unit circle, indicating that the model is very stable. 


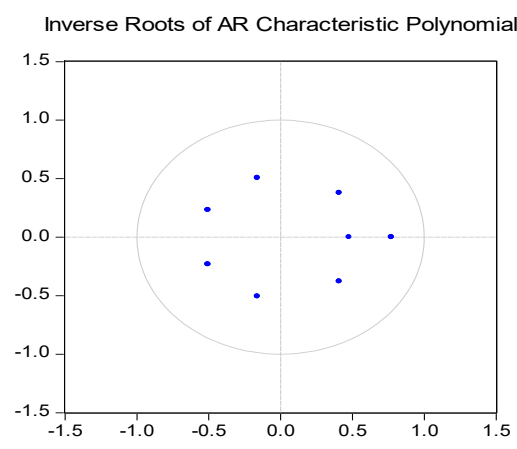

Figure 2 Unstable VAR models cannot do impulse response function analysis, so test the stability

(5)Impulse response analysis of the model.

The impulse response function is used to analyze the dynamic effects of the VAR model on the system under certain impact. Therefore, this paper uses the impulse response function to measure the impact of the balance of the yield and bond interest rate of a standard random impact on their respective dynamic impact path.

Response to Cholesky One S.D. Innovations \pm 2 S.E.

Response of DYEB to DYEB

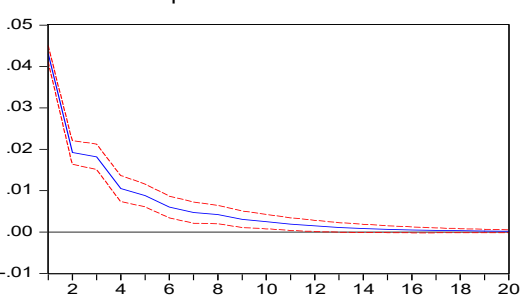

Response of DGZ to DYEB

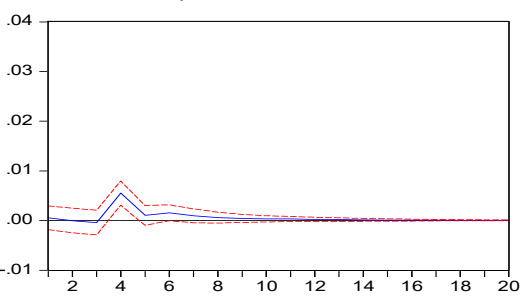

Response of DYEB to DGZ

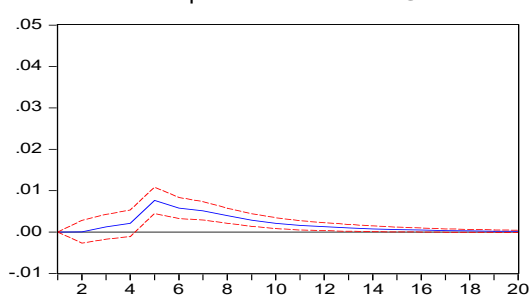

Response of DGZ to DGZ

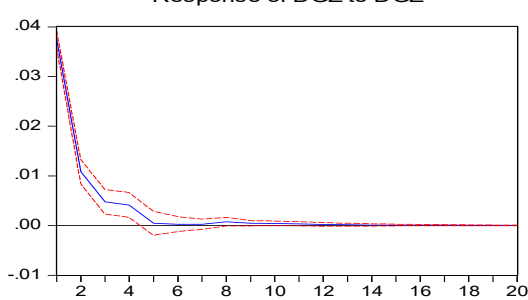

Figure 3 The dynamic process of the effect of the balance of the seven-day annualized rate of return and the one-year maturity rate on the respective impulses.

Figure 3 shows the dynamic process of the effect of the balance of the seven-day annualized rate of return and the one-year maturity rate on the respective impulses. Figure 3 in the upper left shows that the balance of the yield from the beginning of 0.04301 was "J" type of steady decline, and ultimatelyit is in the vicinity of 20 convergences to 0 . Figure 3 in the upper right shows that the balance first increase in profits and then fall, then gradually decline and converge to 0 . According to the lower left figure in Figure 3, Treasury interest rates first flat down, followed by an inverted "V" type of volatility in the final 14 or so convergence to 0 . According to the lower right figure in Figure 3, the national debt interest rate on its own response was "J" type decline; from the initial 0.037455 quickly fell to 0.010834 in the second period. Overall, the four shock response times are short enough.

(6)Variance decomposition

The variance decomposition can give the relative importance of the stochastic information; assess the relative contribution of the Shanghai interbank offered rate and the balance of the balance of the margin. 


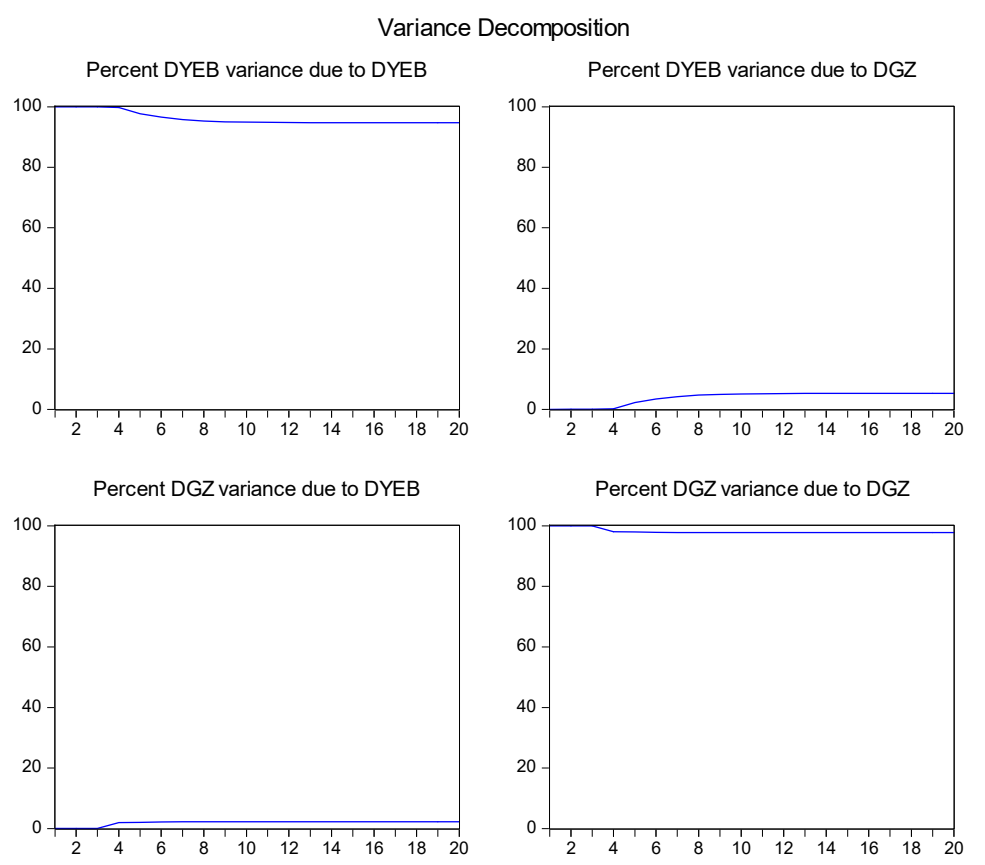

Figure 4 the balance of the yield is mainly affected by its own lag effect

From the results shown in Figure 4, the balance of the yield is mainly affected by its own lag effect, it initially maintained at $100 \%$, from the fourth period it began to gradually approached and eventually maintained at around 95\%. Contribution of Dgz rise from $0 \%$ to $5 \%$. From the results of the variance decomposition of the two graphs in Figure 4, the interest rate of national debt is mainly affected by its own lag effect, which decreases from the initial $100 \%$ and eventually remains around $97 \%$, which shows that the inertia is strong and the duration is long. The relative contribution of dyeb rises from $0 \%$ and eventually remains near $3 \%$.

\section{Empirical analysis}

The balance of treasure yield is mainly affected by their lag, while the national debt interest rate is also an important factor. The current bond interest rate is mainly affected by its own lag, but the balance of the yield is also a non-negligible impact factors. Balance is the representative of the Internet financial products; Treasury interest rates can reflect the status of traditional financial markets. The balance of treasure stirred up the balance of traditional financial markets, breaking the inherent barriers to improve the efficiency of resource allocation, and promote the interest rate market reform.

\section{Suggestions}

The balance of treasure should strengthen the risk management. The balance should strengthen its own management, it attract huge amounts of money with high yields to make rapid growth, but with the interest rate market-oriented reform and financial market perfection, high yield is not sustainable, it should always be alert to liquidity risk. Balance should take full advantage of large data technology to make risk assessment, risk mitigation, security of the user's funds and maintain the stability of the financial market.

The traditional financial markets should update the concept of innovative. The emergence of Internet finance is the inevitable outcome of the development of the market; the traditional financial market should change the traditional concept, enhance service awareness, learn from the advantages of Internet finance, develop new products, and make Internet financial products fair competition. Blindly suppress the Internet financial, refused to innovation and development will only be eliminated by the market, cooperation and competition will promote China's interest rate market reform process, promote the development of China's financial markets. 
The relevant departments should make appropriate and effective supervision and maintenance of financial market security. The Internet financial products have blurred boundaries in the regulatory, legal and other aspects, which caused some difficulties to the relevant regulatory authorities. Therefore, regulators at all levels should coordinate and strengthen cooperation with each other, keep abreast of market dynamics, formulate relevant laws and regulations. At the same time, supervision should avoid too rigid, which ignore the market demand; it should stimulate market vitality, maintain financial market stability and promote the prosperity and development of financial markets.

\section{References}

[1] Zhuang Lei. An Empirical Study on the Fluctuation of the Balance of Profits and Treasury Market [J]. Economics and Management, 2015 (03): 74-79.

[2]Baijie.Research on the Factors Affecting the Return of Balance Poems Based on EEMD-VAR [J]. Modern Finance and Economics, 2015 (08): 80-89.

[3]Wang Ying. Liquidity, Profitability and Risk Analysis of Balance Po [J]. China Business, 2013.

[4]LiaoXuping. Internet Financial Development and Its Risk Supervision Research - Taking P2P Platform, Balance Po and Third Party Payment as an Example [J]. Economics and Management, 2014. 